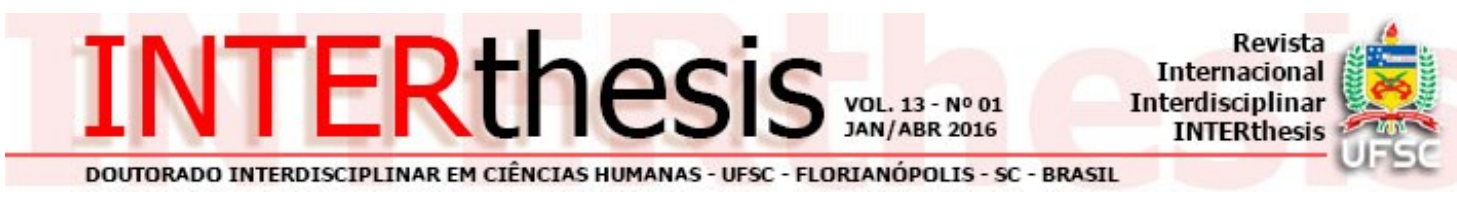

\title{
A LEITURA EM SALA DE AULA COMO MEDIADORA DE CONSTRUÇÃO DE IGUALDADE DE GÊNERO
}

\author{
Marlise Buchweitz Klug ${ }^{1}$ \\ Rosimeire Simões de Lima ${ }^{2}$ \\ Tatiana Bolivar Lebedeff ${ }^{3}$
}

\begin{abstract}
As mãos, porém, não tinham a agilidade da cabeça capaz de perceber sutilezas e ardis. As mãos de Joana eram dois calos, dois montes de terra seca, raízes de árvores os dedos, galhos disformes, mãos acostumadas ao manejo da pá, da picareta, da enxada, do facão, do machado - como manejar lápis, caneta e pena? [...] Rompeu mil pontas de lápis, esgarrachou quantidade de penas, estragou toneladas de papel, mas nessa maratona contra o tempo e as mãos inábeis, Tereza foi de exemplar paciência e Joana, convencida pelos argumentos de Lulu Santos, decidira ganhar, vontade de ferro. Começou Tereza por cobrir a mão tratada a torpe de Joana para lhe transmitir leveza e encaminhá-la. (Jorge Amado)
\end{abstract}

\section{Resumo:}

O presente artigo visa refletir sobre ações em sala de aula que permitem discutir a igualdade de gênero. A partir disso, analisa-se um trabalho com educandos do Ensino Médio das disciplinas de Língua Portuguesa, Literatura e Produção Textual, no qual são trabalhados o vídeo Vida Maria, de Márcio Ramos, e os contos $A$ moça tecelã e Para que ninguém a quisesse, de Marina Colasanti. Os objetivos foram levar ao universo dos alunos a temática de gênero e fazê-los confrontar suas ideias com os textos apresentados, tanto pela leitura e debate dos contos, quanto pela escrita de suas memórias em relação ao lido. A metodologia baseou-se na discussão de assuntos pertinentes aos adolescentes, e na seleção de textos escritos e visuais - que pudessem trazer reflexões sobre o ser mulher, além do trabalho em sala de aula de leitura, discussão e debate sobre os textos, e escrita de análises por parte dos alunos. Os resultados visam a refletir sobre os modos de ser e de agir que se repetem ao longo dos tempos, para os alunos sujeitos críticos e talvez até transformadores da realidade em que vivem.

Palavras-chave: Leitura. Gênero. Igualdade. Memória. Identidade.

\footnotetext{
1 Doutoranda em Memória Social e Patrimônio Cultural pela Universidade Federal de Pelotas, Pelotas, RS. Mestre em Literatura Comparada pela Universidade Federal do Rio Grande do Sul. Bolsista CAPES. Pelotas, RS, Brasil. E-mail: marlise klug@yahoo.com.br

2 Mestre em Educação pela Universidade de Pelotas, Pelotas, RS. Professora nas Disciplinas de Língua Portuguesa, Literatura e Língua Inglesa no Instituto Federal Farroupilha, Campus São Vicente do Sul. São Vicente do Sul, RS, Brasil. E-mail: rosimeiresimoes@gmail.com

${ }^{3}$ Doutora em Psicologia do Desenvolvimento pela Universidade Federal do Rio Grande do Sul. PósDoutorado pela Montgomery County Comunity College em Ambler, Pensilvânia, EUA. Professora da Universidade Federal de Pelotas. Pelotas, RS, Brasil. E-mail: tblebedeff@gmail.com
} 


\section{INTRODUÇÃO}

Ao longo da história da humanidade, têm-se inúmeros casos, exemplos de discriminação dos mais variados possíveis. Dentre eles, os preconceitos e a falta de respeito entre gêneros são temas que nos preocupam enquanto educadores. Essa não é a única questão que media o trabalho docente, mas refletir sobre a mesma e trabalhá-la em sala de aula é sempre urgente, atual e uma ação capaz de trazer resultados efetivos.

Para Goellner et al (2011)

[...] por gênero entende-se a condição social através da qual nos identificamos como masculinos e femininos. É diferente de sexo, termo usado para identificar as características anatômicas que diferenciam os homens das mulheres e vice-versa. O gênero, portanto, não é algo que está dado, mas é construído social e culturalmente e envolve um conjunto de processos que vão marcando os corpos, a partir daquilo que se identifica ser masculino e/ou feminino (p.20).

Por ser algo que se constrói na sociedade, discutir e refletir sobre gênero é questão pertinente para o contexto no qual estamos inseridos. Pesquisas mostram índices altíssimos de violência contra a mulher (DATASENADO, 2013, p. 2-3) e trazer o assunto para dentro da sala de aula é fator importante para gerar a reflexão e permitir o olhar do sujeito sobre sua conduta e seus valores. Destaca-se que o viés de trabalho a ser considerado aqui foi aquele voltado à questão da opressão de um gênero em relação ao outro.

Além disso, gênero pode também ser designado como o verdadeiro aparato de produção através do qual os sexos são estabelecidos e não está para a cultura como o sexo para a natureza; ele é também o significado discursivo/cultural pelo qual a "natureza sexuada" ou o "sexo natural" é produzido e estabelecido como uma forma "pré-discursiva" anterior à cultura, uma superfície politicamente neutra sobre a qual a cultura age (BUTLER, 1990, p. 30). Antes de tudo, a cultura age e nos designa, nos forja, nos encaminha para o que somos e o que seremos dentro de uma pauta pré-estabelecida pelas nossas circunstâncias.

Assim, busca-se sempre inserir a temática da igualdade de gênero no processo contínuo e gradativo que é a docência. Atuando enquanto professoras da área de Linguagens - língua e literatura - busca-se utilizar as ferramentas possíveis 
que a sala de aula oferece: as leituras escolhidas, o contexto sociocultural dos alunos, e a experiência e as vivências pessoais de educador e educandos.

Neste sentido, a presente análise visa a relatar sobre a experiência de trabalhar o vídeo Vida Maria, de Márcio Ramos, e os contos A moça tecelã e Para que ninguém a quisesse da autora Marina Colasanti. Esse trabalho foi desenvolvido durante o ano de 2014 com turmas de Ensino Médio, nas disciplinas de Língua Portuguesa, de Literatura e de Produção Textual. Convém dizer que esta perspectiva de trabalho com gênero é prática recorrente ao longo dos anos de atuação nessa modalidade de ensino da Educação Básica, mas há sempre um novo olhar para a atividade desenvolvida, e o presente artigo é uma reflexão sobre textos usados e metodologias que puderam ser bem aproveitadas.

Destaca-se que "[...] o respeito à diversidade deve permear a prática pedagógica [buscando-se] problematizar esses temas sensibilizando os/as alunos/as para a importância dessa discussão" (Goellner et al, 2011, p. 14). Lembra-se que um experimento realizado em Nova York por uma atriz de uma ONG cujo vídeo filmado durante uma caminhada de dez horas por ruas de Manhattan, nos Estados Unidos, registrou mais de cem comentários de assédio masculinos ${ }^{4}$.Inspirado no vídeo americano, uma jornalista brasileira também grava vídeo com câmera escondida e registra o assédio masculino durante caminhada pelas ruas de Teresina, no Piauí Observa-se, portanto, que em diferentes lugares do mundo a cultura da submissão do gênero feminino é algo recorrente. Deve-se, portanto, trazer o assunto para dentro das escolas, permitindo que os educandos repensem essas atitudes e possam posicionar-se criticamente frente às situações.

Nesta fase da vida dos educandos, nada é mais interessante do que a questão da sexualidade e das diferenças entre gêneros, e já aparecem, mesmo que subentendidos ou de modo implícito, os primeiros sinais de preconceitos. Não há como fugir ou escamotear, pois na sala aparecerá a diversidade. $E$ além da diversidade, há também o fator família que vai incutir ações e maneiras de tratar a questão de gênero e influenciar nas atitudes dos filhos.

\footnotetext{
${ }^{4}$ O vídeo pode ser acessado em https://www.youtube.com/watch?v=b1XGPvbWn0A

${ }^{5}$ A reportagem está disponível em http://noticias.oolho.com.br/noticia/jornalista-faz-experimento-e-sofreassedio-por-2-horas-andando-em-teresina
}

R. Inter. Interdisc. INTERthesis, Florianópolis, v.13, n.1, p.95-113 Jan-Abr. 2016 
Diariamente todos percebem diversos casos de violência contra a mulher, contra os homossexuais, veiculados pela mídia, havendo por vezes até uma banalização desses casos, os quais parecem estar mimetizados na sociedade. Por isso, se ao ler um texto um aluno refletir sobre questões que repete em suas atitudes e pensamentos, ele estará contribuindo para a construção de uma sociedade mais justa, ou para a educação de um modo geral. Desta forma, um trabalho crítico e reflexivo em sala de aula fará com que o educando se posicione de modo diferente em relação a clichês que traz de casa e também em relação a novas situações que porventura poderá vivenciar, e aos problemas que poderá confrontar em sua vida.

\section{A IMPORTÂNCIA DO TRABALHO COM GÊNERO EM SALA DE AULA}

Pensar sobre gênero e sobre todos os desdobramentos que a questão merece é tarefa árdua e com resultados nem sempre imediatos. Cabe à educação parte desse refletir, já que como docentes temos o papel não só de mediar conhecimento científico, mas também de oportunizar reflexões sobre temas do cotidiano da sociedade. Destaca-se que

[...] a construção dos gêneros e das sexualidades dá-se através de inúmeras aprendizagens e práticas, insinua-se nas mais distintas situações, é empreendida de modo explícito ou dissimulado por um conjunto inesgotável de instâncias sociais e culturais. É um processo minucioso, sutil, sempre inacabado. Família, escola, igreja, instituições legais e médicas mantêm-se, por certo, como instâncias importantes nesse processo constitutivo (LOURO, 2008, p. 18).

Para a autora, constantemente especialistas e diferentes revistas, blogs, sites, têm a pretensão de ensinar às mulheres como se vestir, como se portar, como conquistar seu homem, etc. (LOURO, 2008, p. 18-19). Além disso, destaca também a construção da identidade e a voz que provem das minorias, que, nos últimos anos, conquistou espaço e se manifesta contra seus algozes (LOURO, 2008, p. 20).

Assim, um trabalho escolar voltado à discussão dessas questões, do porquê de escritas induzindo as mulheres a serem diferentes, terem determinadas atitudes, e do por que dos brados contra o opressor tomarem espaços cada vez mais amplos, deve ser parte do cotidiano escolar:

R. Inter. Interdisc. INTERthesis, Florianópolis, v.13, n.1, p.95-113 Jan-Abr. 2016 
[...] os movimentos sociais organizados (dentre eles o movimento feminista e os das minorias sexuais) compreenderam, desde logo, que o acesso e o controle dos espaços culturais, como a mídia, o cinema, a televisão, os jornais, os currículos das escolas e universidades, eram fundamentais. A voz que ali se fizera ouvir, até então, havia sido a do homem branco heterossexual. Ao longo da história, essa voz falara de um modo quase incontestável. Construíra representações sociais que tiveram importantes efeitos de verdade sobre todos os demais. Passamos, assim, a tomar como verdade que as mulheres se constituíam no segundo sexo ou que gays, lésbicas, bissexuais eram sujeitos de sexualidades desviantes. Por tudo isso, colocava-se, como uma meta urgente para os grupos submetidos, apropriar-se dessas instâncias culturais e aí inscrever sua própria representação e sua história, pôr em evidência as questões de seu interesse. A luta no terreno cultural mostrava-se (e se mostra), fundamentalmente, como uma luta em torno da atribuição de significados produzidos em meio a relações de poder (LOURO, 2008, p. 20-21).

O primeiro passo do trabalho em sala de aula começa por trazer questionamentos aos alunos, verificar quais são os interesses, saber quais são as dificuldades que possuem em relação à vida, aos estudos, quais seus conflitos, suas histórias de vida, suas posturas frente ao outro, tanto o sujeito outro quanto o gênero diferente, e buscar ouvi-los, enxergando seu entorno. A investigação torna possível a escolha das leituras a serem realizadas ou norteia a direção que se deve seguir. $O$ segundo passo é pedir aos educandos que escrevam sobre suas vidas em forma de diversos mecanismos, desculpas, questionários, relatos, dossiês, livro da vida, fotografia da alma, crachás, memorial, entre outras. A partir dessas atividades, o único objetivo é fazê-los pensar sobre suas vivências e histórias, bem como disponibilizar um variado número de subsídios para conhecer a realidade em que se está trabalhando. Vale destacar que os discentes precisam conhecer quem são, e o que desejam ou não para sua vida e seu futuro. Se a escola não proporcionar a integração e não criar oportunidades de conscientização não terá realizado seu papel ou uma das atribuições a que se destina.

A escrita na vida escolar desses educandos não pode ser considerada como algo natural, em geral. Para uns surgem as reclamações sobre a dificuldade de expor as ideias e a preocupação com o número de linhas, além de falta de vocabulário manifestada na repetição de palavras. Para outros o gosto em escrever e até mesmo certo orgulho em produzir um texto. Geralmente a insistência diária e a aposta em diferentes textos podem mobilizar diversos sentimentos e o aluno escreve em seu ritmo, modo e condição.

R. Inter. Interdisc. INTERthesis, Florianópolis, v.13, n.1, p.95-113 Jan-Abr. 2016 
Após a escrita, o terceiro passo é partir para a leitura de textos, crônicas, reportagens, atualidades, livros, pesquisas, programas, filmes, documentários, entre outros. Nosso foco é pegar o local, analisar quantas denúncias foram feitas na delegacia da cidade, quem os alunos conhecem que já sofreu algum tipo de violência. Pede-se que relatem por escrito quando ou se também já sofreram alguma violência. Acreditamos que é preciso identificar para não permitir reincidências em uma fase tão importante da vida e da formação que é a adolescência. Se permitirem no começo poderão perder longos anos de uma trajetória que não volta, não se repete, mas apenas se esvai no sentido real e figurado também.

A partir disso, torna-se possível confrontar o lido com as experiências pessoais de cada educando, o que possibilita o debate sobre os assuntos polêmicos que permeiam os jornais constantemente. De tal modo que, como debatedor, o aluno possa estar hábil a formular argumentos orais e escritos e inferi-los em diferentes contextos. Acredita-se que um trabalho voltado ao debate sobre assuntos da vida cotidiana permite que o indivíduo, durante sua formação básica, crie mecanismos e argumentos para dizer sim ou não, dentro de suas possibilidades, nas situações que precisará enfrentar em seu dia a dia. Dentre esses assuntos polêmicos, os confrontos e o respeito com o gênero oposto são demandas necessárias para o debate, a reflexão, a formulação de opinião e até a mudança de perspectiva no caso de haver qualquer repressão de um perante o outro.

\section{VIDA MARIA}

O vídeo Vida Maria foi apresentado em sala de aula, no salão da escola e em notebooks para que todos tivessem a oportunidade de assistir. Em seguida à exposição do filme, cada turma debateu e destacou a ligação do conteúdo do filme com suas memórias e deste modo com as mulheres de sua vida. Além disso, comentaram os aspectos que consideraram relevantes ou que chamaram a atenção.

O curta possui a duração de oito minutos e trinta e quatro segundos, lançado em 2006, cujo autor e diretor Márcio Ramos traz a sinopse:

R. Inter. Interdisc. INTERthesis, Florianópolis, v.13, n.1, p.95-113 Jan-Abr. 2016 


\begin{abstract}
"Maria José", uma menina de cinco anos de idade é levada a largar os estudos para trabalhar. Enquanto trabalha, ela cresce casa, tem filhos, envelhece. "Vida Maria" é um filme curta-metragem em animação resultado de um projeto premiado com nota máxima na categoria ficção-animação -35 $\mathrm{mm}$, no edital $3^{\circ}$. Prêmio Ceará de cinema e vídeo, do Governo do Estado do Ceará. Produzido em computação gráfica $3 D$ e finalizado em $35 \mathrm{~mm}$, "Vida Maria" mostra personagens e cenários modelados com texturas e cores pesquisadas e capturadas no Sertão Cearense, no Nordeste do Brasil, criando uma atmosfera realista e humanizada. [...] Encerrou sua carreira de festivais de cinema com mais de cinquenta prêmios nacionais e internacionais, se tornando um dos filmes mais premiados do Brasil. Sua comunicação fácil com o público consegue cativar a mais variada audiência, independente de sua idade, classe, cor, credo, ou nível de escolaridade. "Vida Maria" abre espaço para o debate e tem servido de matéria de apoio e tem servido de material de apoio a mestres e alunos, em projetos sociais, escolares, universitários, palestras, cursos variados, órgãos governamentais e não governamentais por todo o "Brasil".
\end{abstract}

A partir do vídeo e do debate, a atividade de escrita baseou-se na memória de alfabetização dos alunos. Esta atividade foi realizada no mês de março e abril. Em primeiro lugar, a tarefa proposta era resgatar todo o processo de alfabetização que passaram: destacar fatos relevantes, pensar se havia livros na infância, se foi difícil aprender a escrever e ler, qual a importância da leitura e escrita na vida. Também, deviam relembrar se todas as mulheres da família ou de seu entorno passaram pela alfabetização, escrever o modo como a leitura e a escrita pode romper com significativos modelos de opressão que nos rodeiam, e se havia submissão de um gênero em relação ao outro nas questões diárias vivenciadas.

Sempre surge alguma resistência, mas o filme é mobilizador, e provoca o expectador a refletir sobre as inúmeras vidas privadas. Os educandos conseguiram escrever seus memoriais e é curioso como em praticamente todos os textos revelam seus universos letrados e de avós, parentes que passaram uma vida de privações por conta da opressão, da ausência de direitos básicos hoje garantidos por lei, da minimização das mulheres e de seu potencial enquanto sujeitos que pudessem estudar, vivenciar outras experiências. Serviu, ainda, como parâmetro para pensarem a época em que vivem e tudo o que significa o letramento na vida de uma pessoa.

No curta-metragem há um foco destaque para o caso das mulheres, mas se refletiu sobre os homens e os meninos da sala que estão inseridos na turma dos 'sem': sem escolarização, sem trabalho, sem perspectiva. Também, pensou-se sobre o papel da escola e da família na mudança deste cenário, o protagonismo que

R. Inter. Interdisc. INTERthesis, Florianópolis, v.13, n.1, p.95-113 Jan-Abr. 2016 
podemos ter em nossa vida e no rumo que daremos a ela baseado em esforço e determinação.

O encantamento do filme Vida Maria pode estar na simplicidade e ao mesmo tempo na singular vida das personagens. Singular, modo de dizer, plural seria o correto, pois são vidas que aleatoriamente surgem e extinguem-se nas escolas, nas vidas das protagonistas.

Ao longo da exibição podemos observar a cronologia dos fatos com a infância retratada pela Maria na janela desenhando seu nome. Uma infância de ausências. Ausências de brinquedos, cores, mas não deixa de ser uma infância. Entre um afazer e outro, surge o momento fugaz em que pega o caderno e se transporta para outro lugar: o mundo das letras.

Há em Maria de Lurdes um mundo de curiosidades nos olhos, uma vastidão de experiências pela frente quando a mãe, lembrando já foi uma menina sonhadora também, interrompe aquele terno espaço de tempo e arranca a garota literalmente da tentativa de inserção no universo da escrita. A menina, no conforto do parapeito da janela, ajoelhada no banco, olha para o mundo de fora da casa - aquele mundo de chão, trabalho, suor - enquanto que o papel lhe resgata a atenção para outra possibilidade.

No momento em que é advertida por sua mãe, abandona o caderno, com destreza sai correndo para cumprir as tarefas do dia que não terão fim em sua vida, apenas uma continuação. É preciso tratar os bichos, tirar a água do poço, e outros tantos precisos no cotidiano da pequena Maria que já abdicou do lápis e corre porque a mãe não poder esperar e ela não pode permitir-se ao luxo de ficar desenhando seu nome.

Observa-se o destaque para a cultura nordestina: pedir a bênção dos pais e dos mais velhos, tratar de senhora ou senhor, além de demonstrar o delicado afã de uma obediência cega, sem questionamentos. A paisagem também remete ao sertão: chão de terra avermelhada, a presença dos cactos, a falta de vegetação mais densa. Pode-se destacar que o autor quis mesmo chamar a atenção para aquele lugar, fazer uma crítica à vida de lá, e quem sabe direcionar o olhar às condições de vivência das mulheres ali.

R. Inter. Interdisc. INTERthesis, Florianópolis, v.13, n.1, p.95-113 Jan-Abr. 2016 
Mas, observar aquela realidade também remete à realidade de tantas outras mulheres em tantos cantos do Brasil e também permite olhar para o nosso lugar e pensar em questões que afligem as gentes daqui. Percebe-se uma imposição nos olhos da mãe, uma amargura dos anos, a tristeza das agruras já impregnadas na retina que olha para a filha com o rancor de quem está desperdiçando tempo, e talvez sua memória capture o momento em que também ajoelhou no mesmo banco e desenhou no parapeito da janela seu nome. A reprodução do que fazemos muitas vezes está intrínseca, e, sem pensar, repetimos os mesmos conceitos e modos de fazer como se fossem únicos e aceitamos os rótulos como se estivessem corretos.

No vídeo, o autor revela a passagem do tempo mostrando a Maria de Lurdes com uma lata de água na cabeça e quando olha vê Tonho chegando com seu pai. $O$ rapaz mostra a gentileza sempre presente na conquista e se oferece para levar a lata. Ela num dos raros momentos em que sua voz é suave e os olhos transparecem a doçura diz: "Não precisa não, Tonho". Vale destacar a maneira rude com que foi tratada a vida toda em contraposição ao tratamento feito por Tonho: alguém com um olhar que a enxerga e que se oferece a carregar o fardo que the coube ao nascer mulher, pobre, sem perspectivas e sem o direito de ter escolhas - direito apenas a cumprir o ciclo de sua Vida Maria igual a de todas as outras Marias.

Nas seguintes cenas, subtende-se casada e morando na mesma casa de sua infância. Sugere o cenário que nunca saiu daquele território, tudo parece igual. Grávida, muitas vezes a cena se repetirá e mudarão apenas a estampa do vestido e as expressões de envelhecimento do rosto e do cabelo. Conforme passa o tempo, observa-se um encrudecimento da pele e do semblante; se acentua a amargura e aos poucos se cumpre o ciclo de crescer e se multiplicar, com uma mão de pilão socando um alimento. Ao ritmo seco do som do pilão confunde-se a aspereza da sua história: o peso da tarefa bruta de socar os grãos de milho até se transformarem em canjica, ou até o arroz perder a casca. Sugere o impacto do homem sobre a natureza, a imposição de forjar o alimento, das necessidades básicas de alimentação. Passa a mão na testa para afastar o suor. E prossegue agora varrendo o quintal no afã de humanizar a aridez da seca, o capricho com a área externa da casa, a continuação seria a área de lazer, local das rodas de conversa, dos

R. Inter. Interdisc. INTERthesis, Florianópolis, v.13, n.1, p.95-113 Jan-Abr. 2016 
esporádicos descansos, espaço para receber visitas e aproveitar a sombra da árvore que acompanha a narrativa.

O tempo aparece implacável e descortina aos poucos com um "bença mãe" e os filhos entram na pequena casa pela porta principal. Acontece o velório da mãe de Maria de Lurdes e surge na tela a cena que surpreende e retoma o fio condutor da história: novamente a caçula da família está alheia ao que acontece na peça ao lado ajoelhada no banco absorta em seu mundo desenhando nome e nem percebe a aproximação de sua mãe que a arranca da ficção para a realidade e lhe atribui os afazeres como uma sina. Assustada a menina sai correndo, pois é a única opção que lhe resta e o vento aos poucos passa as páginas escritas do caderno com as muitas Marias que passaram por ali e deixaram apenas uma marca na folha em branco. Todas são Maria, não têm sobrenome, nem identidade; a diferença entre elas é o segundo nome de cada uma. E no gesto de arrancar a filha do banco e dos pensamentos distantes, está a memória da mãe que se desiludiu com a vida, que não conseguiu ver nos contornos do lápis um futuro diferente, uma quebra de modos de viver.

Uma mistura de tristeza, indignação e outros sentimentos tomam conta de quem assiste, um desejo de mudar o que sugere ser imutável, o destino e a história de meninas e meninos cujo tempo de vida e as condições que lhes são infligidas não Ihes permite viver a infância e esse tempo efêmero que constituirá todas as outras fases da vida. O período mais delicado no qual a fragilidade que separa o mundo infantil do adulto é constantemente violada pela imposição da força de um adulto, justamente quem deveria ser responsável por alimentar as esperanças, incentivar as mudanças.

Quando o vento toca as páginas e lentamente os nomes surgem em escritas garatujas, disformes, com potencial de escreverem suas histórias, seu presente e futuro ou rememorar o passado: parecem lápides que guardam ou encerram vidas abortadas antes de nascerem. Vidas que quando nem bem despontavam foram todas tolhidas na raiz, na infância tenra e desfolhadas nas folhas de um caderno velho, mas com a possibilidade de uma página em branco.

Muitas vidas são tolhidas, educandos em diferentes lugares perpassam coisas semelhantes em seu caminho. Pode-se observar, através do depoimento de

R. Inter. Interdisc. INTERthesis, Florianópolis, v.13, n.1, p.95-113 Jan-Abr. 2016 
uma aluna, a atribuição de atividades específicas para cada gênero: "[...] minha mãe lavava roupa para fora e meu pai trabalhava na lavoura de arroz; cresci brincando com meus irmãos, e gostava de jogar bola, mas minha mãe dizia que era brincadeira de menino" (ALUNA A, 17 anos).

Assim busca-se realizar o trabalho em sala, com vistas a que os homens e mulheres entendam ou percebam que muitas questões vão além do que parece; muitas estão arraigadas em sua formação familiar e é preciso repensá-las para simplesmente não reproduzi-las. A escrita e o repensar produzem significativas alterações no contexto escolar. A escola cumpre seu papel em incentivar e atuar nessa frente de trabalho por vezes esquecida que é a autonomia e as suas significâncias. $O$ aluno não pode passar o período escolar sem perceber-se e sair da escola sem nela ter estado.

\section{A MOÇA TECELÃ E PARA QUE NINGUÉM A QUISESSE}

Marina Colasanti, através de suas histórias, leva o leitor a refletir sobre a questão da relação entre os gêneros. Os poemas escolhidos para o trabalho em sala de aula permitem levar o educando a pensar sobre o que está por trás da temática lida, o que se pode inferir de reflexão a partir do texto.

Neste sentido, o conto $A$ moça tecelã narra a vida de uma moça que tece suas posses: a casa, o quintal, a luz do dia, a claridade da manhã, o sol, a chuva, a comida, o abrigo, enfim, nada Ihe faltava (COLASANTI, 2012, p. 11). Mas a moça um dia se sentiu só e "[...] pensou como seria bom ter um marido ao seu lado" (COLASANTI, 2012, p. 12). Assim, com capricho de quem tenta uma coisa nunca conhecida, começou a entremear no tapete as lãs e as cores que the dariam companhia (COLASANTI, 2012, p. 12).

A moça ganhou então a companhia de um moço, para quem tudo parecia pequeno e simples demais. Descobrindo o poder da tecelã, pediu-lhe que tecesse uma casa maior, e melhor, a qual mais tarde foi trocada por um palácio. "Dias e dias, semanas e meses trabalhou a moça tecendo portas, e pátios e escadas, e salas e poços. [...] A noite chegava e ela não tinha tempo para arrematar o dia. Tecia e entristecia, enquanto sem parar batiam os pentes [...]" (COLASANTI, 2012, p. 13).

R. Inter. Interdisc. INTERthesis, Florianópolis, v.13, n.1, p.95-113 Jan-Abr. 2016 
Para ela e seu tear, o marido escolheu o mais alto quarto da mais alta torre. "É para que ninguém saiba do tapete - disse. E, antes de trancar a porta a chave, advertiu: - Faltam as estrebarias. E não se esqueça dos cavalos!" (COLASANTI, 2012, p. 13).

Sem descanso, "[...] ela própria trouxe o tempo em que sua tristeza lhe pareceu maior que o palácio com todos os seus tesouros. E pela primeira vez pensou como seria bom estar sozinha de novo" (COLASANTI, 2012, p. 13). Assim, ela "[...] desteceu os cavalos, as carruagens, as estrebarias, os jardins. Depois desteceu os criados e o palácio e todas as maravilhas que continha. E novamente se viu na sua casa pequena e sorriu para o jardim além da janela" (COLASANTI, 2012, p. 14). Por fim,

[...] a noite acabava quando o marido, estranhando a cama dura, acordou e, espantado, olhou em volta. Não teve tempo de se levantar. Ela já desfazia o desenho escuro dos sapatos, e ele viu seus pés desaparecendo, sumindo as pernas. Rápido, o nada subiu-lhe pelo corpo, tomou o peito aprumado, o emplumado chapéu (COLASANTI, 2012, p. 14).

Através desse conto, Colasanti descreve situações vividas por muitas mulheres ao escolherem uma vida a dois: a submissão, o desrespeito, a destituição da liberdade. Mas, basta romper, retomar as rédeas de sua vida. O que nem sempre é o que as mulheres fazem, já que a sociedade ainda não tem um olhar de respeito e acolhimento para com aquelas que escolhem vidas sozinhas.

O conto em questão serve para trazer essa discussão para a sala de aula e incutir nos educandos ideias que possam não só fazê-los repensar os preconceitos existentes no nosso cotidiano, como também refletir sobre as práticas que continuarão exercendo em suas vidas enquanto homens e mulheres que tomarão as rédeas de suas vidas.

O outro conto da autora, Para que ninguém a quisesse, também mostra a relação entre gêneros no sentido da opressão de um pelo outro:

[...] porque os homens olhavam demais para a sua mulher, mandou que descesse a bainha dos vestidos e parasse de se pintar. Apesar disso, sua beleza chamava a atenção, e ele foi obrigado a exigir que eliminasse os decotes, jogasse fora os sapatos de saltos altos. Dos armários tirou as roupas de seda, da gaveta tirou todas as jóias. E vendo que, ainda assim, um ou outro olhar viril se acendia a passagem dela, pegou a tesoura e tosquiou-lhe os longos cabelos. [...] Agora podia viver descansado. Ninguém a olhava duas vezes, homem nenhum se interessava por ela. Esquiva como

R. Inter. Interdisc. INTERthesis, Florianópolis, v.13, n.1, p.95-113 Jan-Abr. 2016 
um gato, não mais atravessava praças. E evitava sair. [...] Tão esquiva se fez, que ele foi deixando de ocupar-se dela, permitindo que fluísse em silêncio pelos cômodos, mimetizada com os móveis e as sombras. Uma fina saudade, porém, começou a alinhavar-se em seus dias. Não saudade da mulher. Mas do desejo inflamado que tivera por ela. Então the trouxe um batom. No outro dia um corte de seda. À noite tirou do bolso uma rosa de cetim para enfeitar-lhe o que restava dos cabelos. Mas ela tinha desaprendido a gostar dessas coisas, nem pensava mais em lhe agradar. Largou o tecido em uma gaveta, esqueceu o batom. E continuou andando pela casa de vestido de chita, enquanto a rosa desbotava sobre a cômoda (COLASANTI, 1986, p. 111-112).

Nele Marina Colasanti retrata a violência simbólica sofrida dentro de muitos lares e silenciada pela depressão, insegurança, medo, pelo lamento de ter investido em um relacionamento e depois não ter condições de dar um basta. Essa percepção dos contos fica clara na escrita de um aluno:

[...] a maioria das mulheres sonha em casar ter um marido perfeito, mas nem sempre é assim que acontece. Alguns querem ser donos da esposa, são violentos, muito ciumentos que chegam ao ponto de cortar os cabelos, tirar as maquiagens e não deixar sua esposa sair de casa. [...] Algumas mulheres têm a coragem de separar, acabar com todo seu sofrimento e seu sonho. Mas outras não têm [essa] coragem e passam toda sua vida vivendo como animal obedecendo seu marido. [...] A conclusão que algumas mulheres têm de se amar mais e ninguém deve ser mandado por outro muito menos pelo seu companheiro que deve amar e respeitar (ALUNO B, 16 anos).

Em contraposição, um depoimento que vai à direção da opressão, do abafamento da vontade do gênero oposto, pode ser observado abaixo:

[...] na minha opinião ele [o personagem do conto] está certo, porque ela [a mulher] não tem o direito de expor suas partes íntimas para os outros; se fosse minha mulher ela não ia usar short curto e nem aquelas blusas ou camisetas decotadas, ela iria usar roupas descentes para que os outros não olhasse para as partes intimas da minha mulher (ALUNO C, 16 anos).

Ainda, observa-se a consciência que os educandos têm das percepções que cada gênero possui em relação ao outro, as quais são acondicionadas a partir de desejos impostos pela sociedade, tais como ter alguém, não ficar só etc.:

[...] ambos os textos da mesma autora tratam histórias que começam iguais, mas uma que tem a vontade de voltar a ser feliz e outra que se intimida pelo marido. Iludidas com a felicidade elas se tornam pessoas sem motivação e sem felicidade. [...] É preciso considerar que todas as pessoas sonham com o par perfeito, fazem coisas absurdas pensando que só assim serão felizes; se tornam propriedade do marido ou da mulher, se tornando incapazes de obter a verdadeira felicidade [...] (ALUNA D, 16 anos).

Desta forma, pode-se destacar que os contos são grandes ferramentas de apoio para um trabalho que, de um modo delicado, mas perspicaz, atinge o ponto

R. Inter. Interdisc. INTERthesis, Florianópolis, v.13, n.1, p.95-113 Jan-Abr. 2016 
crucial e comum à vida das pessoas. Todos em aula podem conhecer alguém que passa ou passou por situações semelhantes. O que deve ficar claro é a certeza de que na vida deles, tanto dos meninos quanto das meninas não permitirão nenhum tipo de violência ou refletirão sobre a mesma. Vale considerar que alguns não identificam como opressão a atitude do parceiro, como é o caso do aluno C. Cabe também aí o papel do professor: é necessário estar atento às questões de gênero que são silenciadas e referidas como normais, aceitáveis (GOELLNER et al, 2011, p. 21).

\section{CONSIDERAÇÕES FINAIS}

Os resultados com o trabalho de leitura e de escrita em sala de aula pode ser um novo olhar sobre as minorias, ou quem sabe a tentativa de fazer um novo caminho. Ao trabalhar com as memórias, com os textos, com o filme Vida Maria, com os poemas 'A moça tecelã' e 'Para que ninguém a quisesse', com a matéria prima que é a vida dos educandos, com os embates diários e a problematização do que é lido e visto diariamente no cotidiano da sociedade, tem-se a certeza de que mudanças favoráveis estão por vir.

Talvez não seja possível mensurar os resultados através de gráficos, mas há várias questões que podem ser observadas com esse trabalho: a mudança de opinião, a fundamentação dos argumentos para respostas, a eliminação de respostas evasivas ou repletas de senso comum, a não repetição de clichês, a não conformação ou aceitação de crimes contra os direitos humanos, a indignação quando uma mulher é agredida ou morta sem contar quando são vítimas das violências simbólicas e psicológicas. Além disso, poder fazer os educandos refletirem que são donas/os de suas vidas e que não necessitam viver como suas avós ou mães ou pais e avôs, que não precisam repetir os modos de agir e de se portar em relação ao gênero oposto.

Salutar se faz saberem que todos são capazes de quebrar ou romper com o ciclo de opressão ou dos que não desejam para a construção de suas vidas. Saber não se deixar corromper por chantagens e ameaças que tiram o significado e o sentido de inúmeras existências.

R. Inter. Interdisc. INTERthesis, Florianópolis, v.13, n.1, p.95-113 Jan-Abr. 2016 
$\mathrm{Na}$ ignorância ou falta de experiência acatam simplesmente os desejos do outro; quando percebem, já não possuem forças para sair de certos relacionamentos. O pior de tudo é que muitos pensam que não acontecerá em sua vida, atribuem a casos isolados publicados em notícias de jornal ou pela mídia.

Os educandos, ao escreverem sobre suas vidas e relacionarem-nas com os textos lidos, podem compreender mais sobre aquilo que precisam vencer a cada dia: suas angústias, seus traumas, os sofrimentos e também as vitórias, esperanças, sorrisos e conquistas. Uma das alunas, comparando sua trajetória com a das muitas Marias do vídeo, destaca que:

[...] a minha mãe tinha muito medo do meu pai, ele era muito violento e nos batia muito. Por um lado foi bom ele ter saído de casa. A gente não podia brincar, sorrir, qualquer coisa era motivo para uma briga; muitas vezes a minha mãe apanhava junto com a gente (ALUNA F, 15 anos).

Outro detalhe recorrente nas escritas memoriais era o menosprezo dos pais (homens) em relação ao nascimento de filhas mulheres: "[...] nasci em casa, meu pai que fez meu parto e o de meus irmãos; quando eu nasci ele não me queria porque eu era menina, ele queria só filhos homens [...]" (ALUNA G, 16 anos). Esse fato foi mencionado em diferentes relatos, e observa-se, através dele, um sentimento de repúdio e indiferença sentido por essas meninas.

Neste sentido, através do relato, surgem as histórias que compõem a identidade desses indivíduos que hoje estão enfrentando caminhos e buscando dias melhores através da educação. Observa-se que a escolha dos textos dos alunos aqui transcritos não teve qualquer caráter meritório. Assim como os exemplos trazidos, muitos outros textos poderiam ter sido usados neste trabalho. A cada ano, a cada nova turma com a qual é trabalhada a questão relativa a gênero, muitos depoimentos semelhantes são observados e trazidos para a sala de aula. Histórias de meninos e meninas que vivem opressão, dificuldades e carências de apoio para romper com situações comuns.

Destaca-se que nossa vida se completa e se funde com a vida de tantas mulheres que nasceram nesse século e tiveram a oportunidade de ver o crescimento e as conquistas. Porém, vale lembrar que esse direito foi pensado, gestado, construído. Temos em nossas mãos uma preciosa oportunidade de trabalhar com a educação e numa profissão que oportuniza o contato diário com adolescentes e 
adultos, pessoas que estão em formação e que precisam pensar suas escolhas, pois elas terão reflexo no presente e no futuro de seus descendentes. É preciso uma escolha muito consciente e segura.

Trabalhar com os inúmeros recursos que os professores possuem na atualidade é um privilégio e não se pode perder essa oportunidade de crescer e fazer o grupo crescer também. É um processo gradativo que nos leva a pensar repensar. Os escritos, vídeos, poemas, crônicas, debates entre outros nos permitem tecer um conjunto de argumentos e subsídios para a defesa de nossos posicionamentos e da vida em construção dentro de suas condições peculiares. Seria pretensão afirmar, mas ao construir a prática oportunizam-se reflexões e autoestima que permitam que os alunos tenham avançado e saibam se mobilizar ao ponto de saber dizer não. 


\title{
CLASSROOM READING AS MEDIATOR FOR GENDER EQUALITY CONSTRUCTION
}

\begin{abstract}
:
The present essay aims to reflect about actions in classrooms that enable discussions about gender equality, since the minorities' literature is even more important. Among them, the literature that exposes the suffering, the livingness, the traumas, and women's oppression is central to lead us to the basic education classroom universe, its reflections and theorizations. So, the present text proposes an analysis of a project built with High School students in classes such as Portuguese language, Literature and Textual production. This work comprehends a video untitled Vida Maria, by Marcio Ramos, and two tales named $A$ moça tecelã and Para que ninguém a quisesse, by Marina Colassanti. The purpose of this work was to lead students to the gender theme and to make them confront their own impressions about selected and presented texts, by reading or debating gender issues, and by writing memories that related their life experiences with what was read. The methodology was based on the discussion of relevant issues for teenagers and of the choice of the 'gender' theme, mainly because questions involving sexuality made them anxious. Later, a selection of texts - written and visual - was made in order to create a classroom discussion and debate about the texts, and also a written analysis by the students was done. Short-term results do not always occur, but it is expected that, through a work focusing on gender differences, it is possible to influence in society's vision on women, and to make students aware they can transform the reality in which they live.
\end{abstract}

Keywords: Reading. Gender. Equality. Memory. Identity.

\section{LA LECTURA EN SALÓN DE CLASES COMO MEDIADOR EN LA CONSTRUCCION DE IGUALDAD DE GÉNERO}

\section{Resumen:}

El presente artículo tiene como objetivo reflexionar sobre las acciones en el salón de clases que permiten discutir la igualdad de género. A partir de esto, se analisa un trabajo realizado con los estudiantes de la Escuela Secundaria, en las materias de Lengua Portuguesa, Literatura y Producción Textual, en la cual son trabajados lo video Vida María, de Márcio Ramos, y los cuentos A moça tecelã y Para que ninguém a quisesse, de Marina Colasanti. Los objetivos fueron los de traer al universo de los estudiantes las cuestiones de género y hacerlos confrontar sus ideas con los textos presentados, tanto en la lectura, debates de los cuentos y escribiendo sus memorias en relación a lo leído. La metodología se baseó en la discusión de temas relevantes para los adolescentes y en la selección de los textos - escrito y visual - que lograran aportar reflexiones sobre el ser una mujer, además del trabajo en la sala de aula de lectura, discusión y debates sobre los textos, y escritura de los análisis por parte de los alumnos. Los resultados procuran una reflexión sobre las mujeres, las formas de ser y de actuar, que se repiten a lo largo del tiempo, pueda logra que los estudiantes obtengan un cuestionamiento crítico del tema y tal vez hasta transformar la realidad en la que viven.

Palabras clave: Lectura. Género. Igualdad. Memoria. Identidad. 


\section{REFERÊNCIAS}

10 HOURS WALKING IN NYC AS A WOMAN. Diretor e Produtor: Rob Bliss. Vídeo. 1 min 56 s. 2014.

AMADO, Jorge. Tereza Batista cansada de guerra, 1972, p.46.

BARRETO, Sávia. Jornalista faz experimento e sofre assédio por duas horas andando em Teresina. In: O olho, 2014. Disponível em

http://noticias.oolho.com.br/noticia/jornalista-faz-experimento-e-sofre-assedio-por-2horas-andando-em-teresina Acesso em: 25 ago. 2015.

BUTLER, J. Gender trouble. Feminism and the subversion of identy. New York: Routeledge, 1990.

COLASANTI, Marina. Para que ninguém a quisesse. In: Contos de amor rasgados. Rio de Janeiro: Rocco, 1986. pp. 111-112.

. A moça tecelã. In: Um espinho de marfin \& outras histórias. Porto Alegre: L\&PM, 2012. pp. 11-14.

DATASENADO. Violência Doméstica e Familiar Contra a Mulher. Secretaria de Transparência, 2013. Disponível em http://www.senado.gov.br/senado/datasenado/pdf/datasenado/DataSenadoPesquisa-Violencia Domestica contra a Mulher 2013.pdf Acesso em: 21 ago. 2015.

EL-JAICK, Márcio. No presente. São Paulo: GLS, 2008. ISBN 978-85-86755-51-4. Disponível em www.igualdadedegenero.cnpq.br. Acesso em: 11 out. 2012.

GOELLNER, Silvana V.; et al. Corpos, gêneros, sexualidades e relações étnicoraciais: reflexões a partir de uma experiência em sala de aula. In: SILVA, Fabiane Ferreira; MELLO, Elena Maria B. (orgs.). Corpos, gêneros, sexualidades e relações étnico-raciais na educação [recurso eletrônico] - Uruguaiana, RS: UNIPAMPA, 2011. Disponível em http://porteiras.r.unipampa.edu.br/portais/sisbi/files/2013/07/Corpos2011.pdf Acesso em 07 dez. 2015. 
LOURO, Guacira Lopes. Gênero e sexualidade: pedagogias contemporâneas. In: Pro-Posições, v. 19, n. 2 (56) - maio/ago 2008, p. 17-23. Disponível em http://www.scielo.br/pdf/pp/v19n2/a03v19n2.pdf. Acesso em 14 ago. 2015

PÁTIO. Porto Alegre: Artmed. 2008. Trimestral.

VIDA MARIA. Produção: Márcio Ramos. Curta-metragem. 3 D. 35 mm. 8 min 34 s. 2006.

VEJA. São Paulo: Editora Abril. 2010. Semanal.

\section{Artigo}

Recebido em 04 de Setembro de 2015

Aceito em 01 de Janeiro de 2016

R. Inter. Interdisc. INTERthesis, Florianópolis, v.13, n.1, p.95-113 Jan-Abr. 2016 